\title{
Erratum to: Changes in the pneumococcal disease-related hospitalisations in Spain after the replacement of 7-valent by 13 -valent conjugate vaccine
}

\author{
L. Georgalis $^{1,2}$ • A. Mozalevskis ${ }^{1,2}$ • M. V. Martínez de Aragón ${ }^{1,3} \cdot$ M. Garrido-Estepa ${ }^{1,4}$
}

Published online: 5 October 2017

(C) Springer-Verlag GmbH Germany 2017

Erratum to: Eur J Clin Microbiol Infect Dis (2017) 36:575-583

https://doi.org/10.1007/s10096-016-2834-2

The original version of this article was published online with an incorrectly arranged Table 2. Also, Figs. 1 and 2 were missing the legends. The corrected table and figures are provided below.

The online version of the original article can be found at https://oi.org/ 10.1007/s10096-016-2834-2

\section{Garrido-Estepa}

mgarrido@isciii.es; macarena.gaes@gmail.com

1 National Centre for Epidemiology, Carlos III Health Institute (ISCIII-CNE), Madrid, Spain

2 European Programme for Intervention Epidemiology Training (EPIET), European Center for Disease Prevention and Control (ECDC), Stockholm, Sweden

3 CIBER Epidemiología y Salud Pública (CIBERESP), Madrid, Spain

4 Health Technology Assessment Agency, Carlos III Health Institute (ISCIII-CNE), Av. Monforte de Lemos N5, 28029 Madrid, Spain 


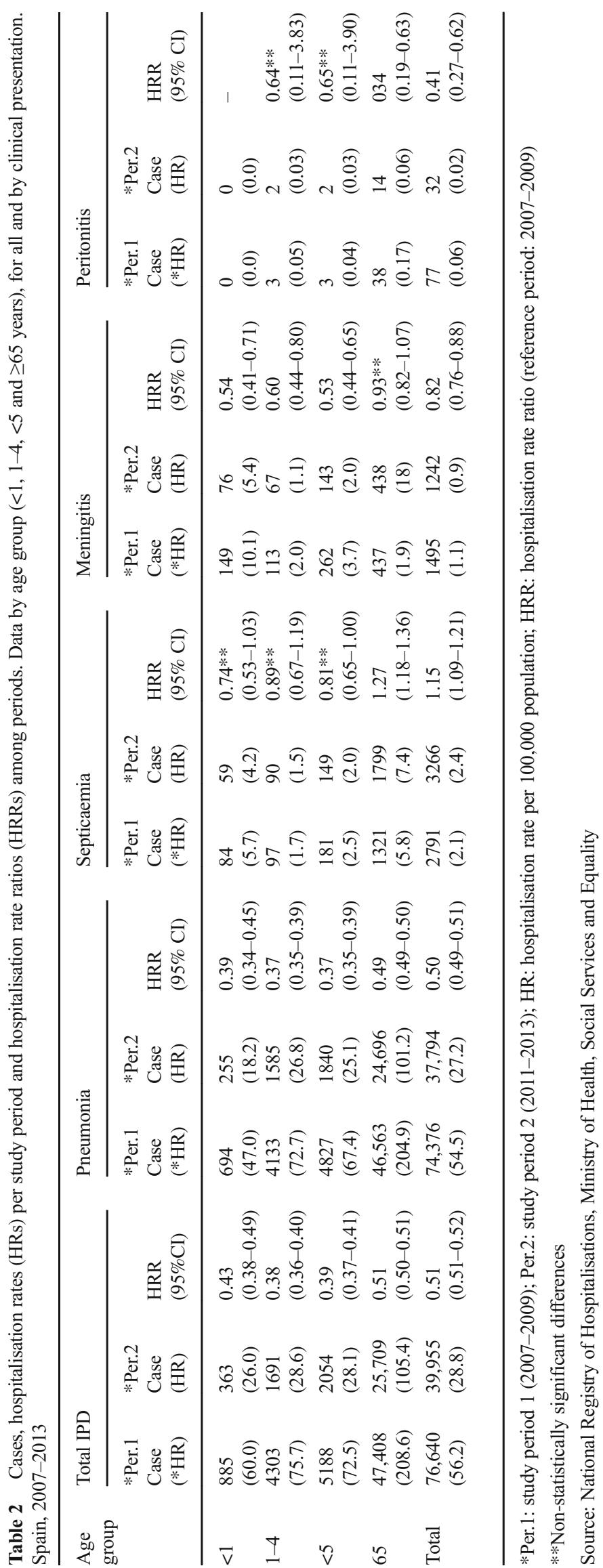




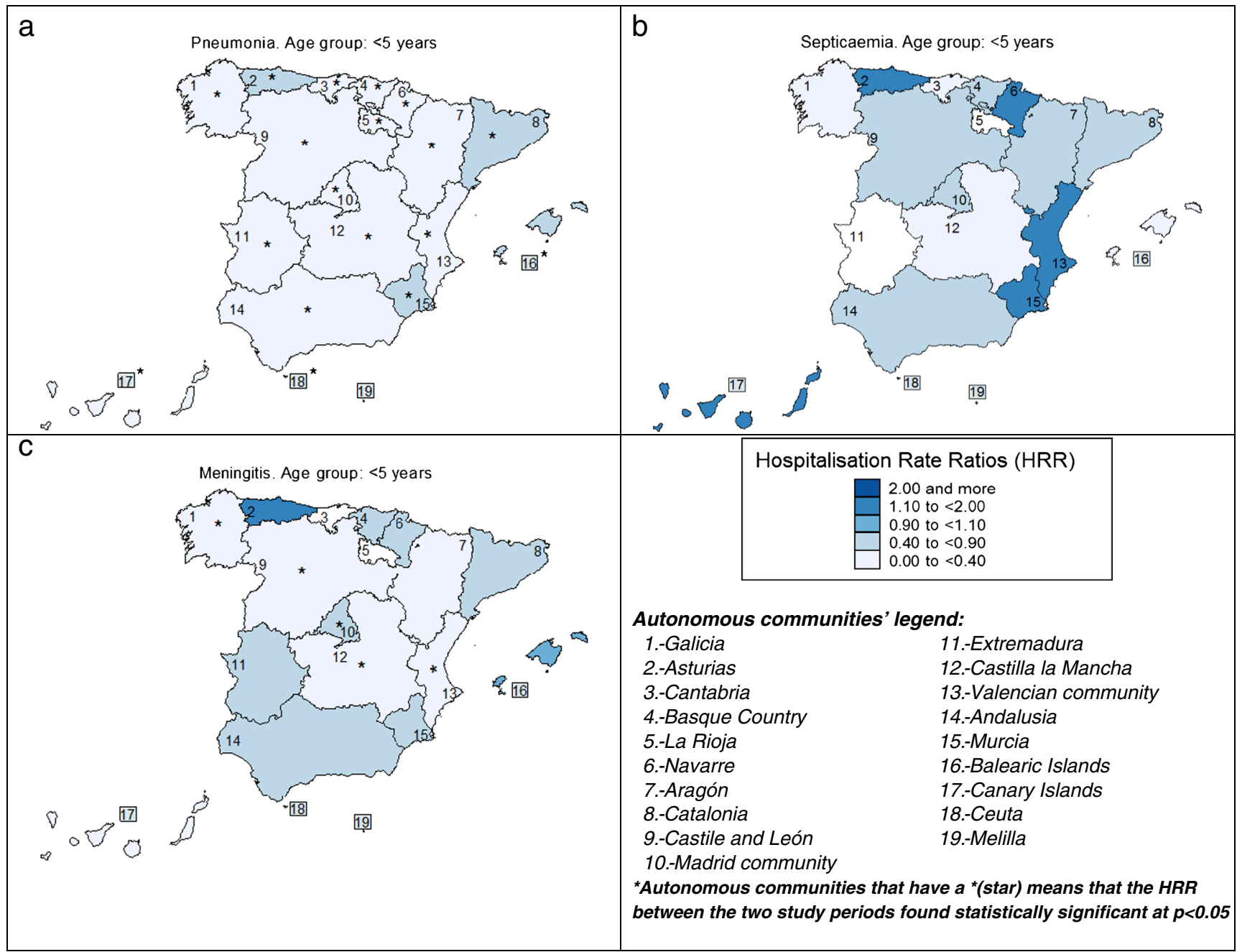

Fig. 1 Hospitalisation rate ratios (HRRs) in children $<5$ years old for pneumococcal pneumonia, septicaemia andmeningitis by autonomous community in Spain 


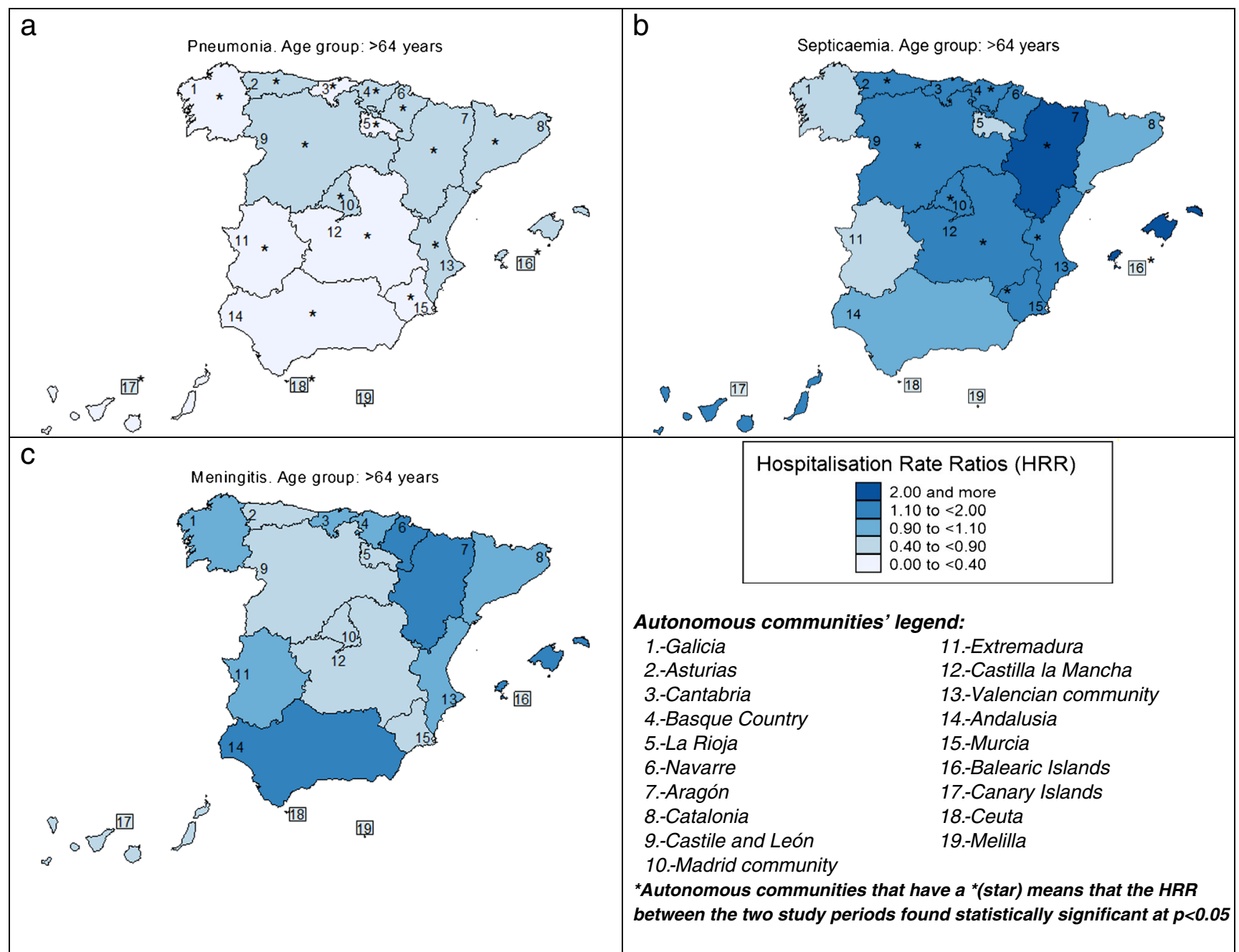

Fig. 2 Hospitalisation rate ratios (HRRs) in the adults $\geq 65$ years old population for pneumococcal pneumonia, septicaemia and meningitis by autonomous community in Spain 